\title{
Variation in Oxytocin Receptor Density in the Nucleus Accumbens Has Differential Effects on Affiliative Behaviors in Monogamous and Polygamous Voles
}

\author{
Heather E. Ross, ${ }^{1,2}$ Sara M. Freeman, ${ }^{1,2}$ Lauren L. Spiegel, ${ }^{1,2}$ Xianghui Ren ${ }^{4,5}$ Ernest F. Terwilliger, ${ }^{4}$ and \\ Larry J. Young ${ }^{1,2,3}$ \\ ${ }^{1}$ Center for Behavioral Neuroscience, ${ }^{2}$ Yerkes National Primate Research Center, and ${ }^{3}$ Department of Psychiatry and Behavioral Sciences, School of \\ Medicine, Emory University, Atlanta, Georgia 30033, and ${ }^{4}$ Harvard Institutes of Medicine and ${ }^{5}$ Beth Israel Deaconess Medical Center, Boston, \\ Massachusetts 02115
}

Oxytocin receptors in the nucleus accumbens have been implicated in the regulation of alloparental behavior and pair bond formation in the socially monogamous prairie vole. Oxytocin receptor density in the nucleus accumbens is positively correlated with alloparenting in juvenile and adult female prairie voles, and oxytocin receptor antagonist infused into the nucleus accumbens blocks this behavior. Furthermore, prairie voles have higher densities of oxytocin receptors in the accumbens than nonmonogamous rodent species, and blocking accumbal oxytocin receptors prevents mating-induced partner preference formation. Here we used adeno-associated viral vector gene transfer to examine the functional relationship between accumbal oxytocin receptor density and social behavior in prairie and meadow voles. Adult female prairie voles that overexpress oxytocin receptor in the nucleus accumbens displayed accelerated partner preference formation after cohabitation with a male, but did not display enhanced alloparental behavior. However, partner preference was not facilitated in nonmonogamous meadow voles by introducing oxytocin receptor into the nucleus accumbens. These data confirm a role for oxytocin receptor in the accumbens in the regulation of partner preferences in female prairie voles, and suggest that oxytocin receptor expression in the accumbens is not sufficient to promote partner preferences in nonmonogamous species. These data are the first to demonstrate a direct relationship between oxytocin receptor density in the nucleus accumbens and variation in social attachment behaviors. Thus, individual variation in oxytocin receptor expression in the striatum may contribute to natural diversity in social behaviors.

Key words: maternal; virus; preference; neuropeptide; cognition; autoradiography

\section{Introduction}

Microtine rodents display a remarkable diversity in social behaviors, ranging from highly affiliative and socially monogamous to relatively asocial and promiscuous mating strategies (Gruderadams and Getz, 1985). The socially monogamous prairie vole ( $\mathrm{Mi}$ crotus ochrogaster) forms enduring social attachments, or pair bonds, to an opposite-sex partner following cohabitation and mating, while nonmonogamous meadow voles (Microtus pennsylvanicus) typically do not. Adult sexually naive female prairie voles display considerable diversity in their spontaneous nurturing behavior, or alloparental behavior, with approximately half showing maternal-like behavior toward pups while the remainder either ignore or attack pups (Lonstein and De Vries, 1999; Bales and Carter, 2003; Olazábal and Young, 2005). Thus voles

Received 0ct. 16, 2008; revised Dec. 6, 2008; accepted Dec. 18, 2008.

This work was supported by National Institutes of Health Grants MH064692 to L.J.Y. and RR00165 to Yerkes National Primates Research Center and by National Science Foundation Science and Technology Center Agreement IBN-9876754. We thank Lorra Mathews for her excellent job managing our vole colony.

Correspondence should be addressed to Larry J. Young, 954 Gatewood Road, Yerkes National Primate Research Center, Emory University, Atlanta, GA 30322. E-mail: lyoun03@emory.edu.

D01:10.1523/JNEUROSCI.5039-08.2009

Copyright $\odot 2009$ Society for Neuroscience $\quad$ 0270-6474/09/291312-07\$15.00/0 provide an excellent opportunity to examine the neurobiological mechanisms underlying social attachment and alloparental care, as well as the mechanisms leading to diversity in these behaviors both across species and between individuals.

The nonapeptide oxytocin (OT) has been implicated in the regulation of both partner preference formation and alloparental behavior in prairie voles. Infusion of an oxytocin receptor (OTR) antagonist into the nucleus accumbens (NAcc), but not into the adjacent caudate-putamen, blocks mating-induced partner preference formation, a laboratory proxy of pair bond formation (Young et al., 2001). Similar infusions of OTR antagonist into the NAcc also block alloparental behavior in virgin females (Olazábal and Young, 2006b). Thus activation of OTRs in the NAcc facilitates both partner preference formation and alloparental behavior in female prairie voles.

Variation in OTR density in the NAcc has been hypothesized to contribute to species differences in social organization and alloparental behavior. Prairie voles have high densities of OTR in the NAcc, while nonmonogamous meadow voles, mice, and rats do not (Insel and Shapiro, 1992; Olazábal and Young, 2006a). Prairie voles also display higher levels of alloparental behavior than do meadow voles, mice, or rats (Olazábal and Young, 
2006a). Paralleling this interspecies relationship between OTR density in the NAcc and parental behavior, OTR density in the NAcc is positively correlated with alloparental behavior in both juvenile and adult female prairie voles (Olazábal and Young, 2006a,b). In this study, we used adeno-associated viral vector (AAV) gene transfer to directly test the hypothesis that variation in NAcc OTR density can contribute to variation in social attachment and alloparental behavior. Adult female prairie voles were bilaterally infused into the NAcc with an AAV encoding the prairie vole OTR gene, resulting in a significant elevation in OTR binding. Animals were then tested for alloparental behavior and partner preference formation. We then tested the hypothesis that OTR expression in the NAcc was sufficient to facilitate partner preference formation by infusing female meadow voles with the same vector. We predicted that compared to controls, OTRoverexpressing female prairie voles would show increased alloparental behavior and accelerated partner preference formation. Furthermore, we predicted that meadow vole females expressing OTR in the NAcc would develop partner preferences toward male partners.

\section{Materials and Methods}

Animals. Prairie and meadow voles were housed in same sex groups with 2-3 voles/cage from the time of weaning at 21-23 d of age. Housing consisted of a ventilated $36 \times 18 \times 19 \mathrm{~cm}$ Plexiglas cage filled with Bed-ocobbs Laboratory Animal Bedding under a 14:10 h light/dark cycle at $22^{\circ} \mathrm{C}$ with access to food (rabbit LabDiet) and water ad libitum. The prairie voles were obtained from our laboratory breeding colony that originally derived from field-captured voles in Illinois. Meadow voles were derived from stock obtained from a breeding colony at Florida State University. Subjects were 2- to 5-month-old intact sexually naive female voles. Stimulus animals were sexually experienced adult male voles. Each male served as a "partner" and a "stranger" during the partner preference test (see below). Littermates were assigned to different treatment groups to control for variability within litters and within cages. All procedures were approved by the Emory University Institutional Animal Care and Use Committee.

Adeno-associated viral vectors. The OTR coding sequence was created by splicing the first exon of a prairie vole OTR genomic clone encoding the first five transmembrane domains (GenBank accession number AF079980) and the 3' end of the OTR amplified from prairie vole uterus cDNA. The coding sequence was reframed using PCR to eliminate the UTRs and provide new flanking restriction sites to facilitate cloning into the AAV vector plasmid. The modified gene was then cloned into an AAV2 vector plasmid between a $0.6 \mathrm{~kb}$ cytomegalovirus (CMV) promoter and a SV40 DNA fragment containing the SV40 small t intron and polyA signal. The AAV2-OTR was cross-packaged in AAV9 by a triple plasmid transfection into AAV-293 cells (Stratagene) using a standard calcium phosphate precipitation method. No helper virus was used. An AAV2-eGFP plasmid was packaged in parallel in AAV9 as a negative control vector. Briefly, each AAV vector plasmid, an AAV2/9 rep/cap plasmid providing AAV2 replicase and AAV9 capsid functions, and a third plasmid encoding Adenovirus helper functions, pHelper (Stratagene), were cotransfected into 293 cells at a molar ratio of 1:1:1. Cells were harvested $48 \mathrm{~h}$ after transfection. The cell pellets were then resuspended in DMEM, and the intracellular virus particles released by three consecutive rounds of freeze-thaw, followed by centrifugation at 13,000 rpm for $10 \mathrm{~min}$ on a table-top centrifuge to remove particulates. The vector stocks were stored at $-80 \mathrm{C}$, and titered by real-time PCR using an ABI Prism 7700 Sequence Detection System from Perkin-Elmer Applied Biosystems. Titers were on the order of $10^{12}$ DNase-resistant particles $/ \mathrm{ml}$.

Viral vector infusion. Stereotaxic infusions were performed under isoflurane anesthesia in a Kopf stereotax fitted with an Ultra Micro Pump II (World Precision Instruments) and a 26 gauge Hamilton syringe. Females were injected bilaterally into the shell of the NAcc [prairie voles: anteroposterior $(\mathrm{AP})+1.7 \mathrm{~mm}$, mediolateral (ML) $0.9 \mathrm{~mm}$, dorsoven$\operatorname{tral}(\mathrm{DV})-4.5 \mathrm{~mm}$, meadow voles: AP $+1.6 \mathrm{~mm}$, ML $0.9 \mathrm{~mm}$, DV -4.3 $\mathrm{mm}$ ] with $750 \mathrm{nl}$ of either an AAV containing the vole oxytocin receptor (CMV-OTR, $n=12$ ) or a control eGFP-expressing vector (CMV-GFP, $n=16$ ). Virus was infused at a rate of $93.8 \mathrm{nl} / \mathrm{min}$. The syringe was left in place for 5 min following infusion to minimize diffusion of vector up the needle track. Sham-operated animals $(n=9)$ were anesthetized and had their scalps incised and sutured. Following surgery, animals were group housed until time of partner preference behavior testing. Preliminary studies indicated that OTR expression at the site of injection was stable after $10 \mathrm{~d}$.

Alloparental behavior testing. One month after injection, the prairie voles were tested for alloparental behavior. Testing occurred between 8:00 A.M. and 6:00 P.M. Test animals were placed in a large clean cage $(45.5 \times 24 \times 20 \mathrm{~cm})$ and allowed to acclimate for $15 \mathrm{~min}$. Two pups $(2-5$ $\mathrm{d}$ of age) were placed on one end of the cage. The latency to approach the pups, number of animals that attacked pups, and the amount of time spent grooming, hovering, and retrieving the pups were recorded. A latency of $900 \mathrm{~s}$ was assigned to animals that did not approach the pups during the $15 \mathrm{~min}$ test for the purpose of statistical analysis. Testing was immediately stopped if the female attacked the pups. Animals were categorized as alloparental if they spent $>30$ s licking the pups without attacking. Based on the results from the experiment with prairie voles, meadow voles were not tested for alloparental behavior.

Partner preference testing (prairie vole). One month following the alloparental behavior testing, and 2 months following AAV infusion, females were given $4 \mu \mathrm{g}$ of estradiol benzoate (EB; Fisher) dissolved in $0.1 \mathrm{ml}$ of sesame oil intraperitoneally daily for $3 \mathrm{~d}$ before mating to induce sexual receptivity. Sixteen hours following the last EB injection, animals were placed in a clean cage $(28 \times 17 \times 12 \mathrm{~cm})$ with a sexually experienced adult male for $6 \mathrm{~h}$ and then returned to group housing. Mating behavior was recorded during the initial $6 \mathrm{~h}$ cohabitation. The latency to first intromission and the number of mating bouts in the first hour were scored. A latency of $3600 \mathrm{~s}$ was assigned to animals that did not mate during the $1 \mathrm{~h}$ period for the purpose of statistical analysis. The following morning ( $14 \mathrm{~h}$ after the cohabitation), the animals were tested for partner preference. In a partner preference test, the experimental female is placed in a neutral center chamber of a three-chambered apparatus, in which the partner male is tethered in one side chamber and a novel "stranger" male is tethered in the other (Williams et al., 1992). The experimental animal is free to move throughout the chambers and the time spent in close proximity to each male is recorded using an automated beam break system (Curtis and Wang, 2005a,b; Lim et al., 2007).

A day later, the females were repaired with the same partner for an additional $12 \mathrm{~h}$ of cohabitation. The females were then tested again for a partner preference ( $18 \mathrm{~h}$ total contact time). This two-stage paradigm was used to maximize our detection of a facilitation of partner preference test, since there is variability in the threshold time needed to form a partner preference. Animals were considered to have a partner preference if they spent twice as much time in close proximity with the partner compared with the stranger.

Partner preference testing (meadow vole). Typically meadow voles from our colony will not form a pair bond after $24 \mathrm{~h}$ of mate exposure. Therefore for this experiment, partner preference tests were performed after a cohabitation of 24 and an additional $48 \mathrm{~h}$ ( $72 \mathrm{~h}$ total). All other treatment and testing methods are the same as above.

Tissue collection and processing. Following the behavioral experiments animals were decapitated following deep anesthetization with isoflurane. Brains were then collected and frozen on powdered dry ice. The brains were sectioned through the NAcc in 6 series at $20 \mu \mathrm{m}$, on a cryostat, onto Fisher Frost-plus slides. Slides were stored at $-80 \mathrm{C}$ until used in autoradiography.

OTR autoradiography. OTR receptor autoradiography was used to assess OTR binding in AAV-injected animals. Autoradiography was performed as described previously with slight modifications (Insel et al., 1991; Wang and Young, 1997). Sections were removed from - 80C storage, allowed to air, dipped in $0.1 \%$ paraformaldehyde in PBS, pH 7.4, and rinsed twice in $50 \mathrm{~mm}$ Tris buffer, $\mathrm{pH}$ 7.4, to remove endogenous OT. Next the tissue was incubated in 50 pM ${ }^{125}$ I-OVTA (NEX 254050UC PerkinElmer) for $1 \mathrm{~h}$. Unbound radioligand was removed by four washes in $50 \mathrm{~mm}$ Tris plus $2 \% \mathrm{MgCl}_{2}, \mathrm{pH} 7.4$, and then dipped into $\mathrm{dH}_{2} \mathrm{O}$ and air dried under a stream of cool air. Once dry, the slides were exposed to 
BioMax MR film (Kodak) for $72 \mathrm{~h}$. Two CMV-OTR and one CMV-GFP animals were excluded from the behavioral analysis due to injection misses.

GFP immunohistochemistry. A subset of the animals $(n=5)$ injected with CMV-GFP was perfused transcardially with $50 \mathrm{ml}$ of PBS, followed by $50 \mathrm{ml}$ of $4 \%$ paraformaldehyde in $0.1 \mathrm{M}$ phosphate buffer containing $2.5 \%$ acrolein (Polysciences). Immediately following perfusion, the brains were removed and stored at $4^{\circ} \mathrm{C}$ in $30 \%$ sucrose solution until sectioning. The brains were cut into $25 \mu \mathrm{m}$ coronal sections with a freezing microtome and stored free-floating in cryoprotectant solution at $-20^{\circ} \mathrm{C}$ until immunohistochemical processing.

A 1:6 series through the rostrocaudal axis of each brain was processed for GFP. Briefly, sections were removed from the cryoprotectant solution, rinsed extensively in potassium PBS (KPBS), $\mathrm{pH}$ 7.4, and then reacted for $15 \mathrm{~min}$ in $1 \%$ sodium borohydride to remove excess aldehydes. Sections were then incubated in primary antibody solution directed against GFP in KPBS containing $0.1 \%$ Triton-X for $1 \mathrm{~h}$ at room temperature followed by $48 \mathrm{~h}$ at $4^{\circ} \mathrm{C}$. Cells containing GFP were identified by using a polyclonal rabbit anti-GFP antibody (Cat. No. A6455, Invitrogen) at a concentration of 1:100,000. After primary antibody incubation, the tissue was rinsed in KPBS, incubated for $1 \mathrm{~h}$ in biotinylated goat anti-rabbit IgG (Jackson ImmunoResearch) at a concentration of $1: 600$, and rinsed in KPBS, followed by a $1 \mathrm{~h}$ incubation in avidin-biotin peroxidase complex (ABC Elite Kit PK-6100 Vector) at a concentration of 1:200. After rinsing in KPBS and Tris buffer, pH 7.2, GFP was visualized as a brown reaction product by using $3,3^{\prime}$-diaminobenzidine containing $0.08 \%$ hydrogen peroxide in Tris buffer. The reaction product was terminated after $\sim 20 \mathrm{~min}$ by rinsing in Tris buffer. Sections were mounted out of saline onto gelatin-subbed slides, air dried, dehydrated in a series of graded alcohols, cleared in Histoclear (National Diagnostics), and coverslipped using Krystalon (EMD Chemicals).

Statistical analysis. Data are presented as mean \pm SEM. A two-way RM ANOVA was run using time spent with each stimulus animal as the dependent variable, partner or stranger as the within-subjects factor, and treatment group as the between-subjects factor. The Holm-Sidak test was used for post hoc pairwise comparisons when a significant interaction effect was detected. One-way ANOVAs were run on alloparental and mating behaviors for prairie voles. Those behaviors that did not meet the criteria for normality were analyzed using the Kruskal-Wallis one-way ANOVA on ranks. A Fisher's exact test was used to determine group differences in the proportion of animals displaying alloparental behavior. Meadow vole mating behavior was analyzed using a $t$ test and MannWhitney rank-sum test when the normality test failed.

\section{Results}

\section{Alloparental behavior in prairie voles}

The proportion of CMV-OTR-injected female prairie voles displaying alloparental behavior (3/9) did not differ from the control $(4 / 15)$ or sham voles $(3 / 10)(p>0.5)$ (Fig. $1 A)$. Two CMVOTR, four CMV-GFP control, and two sham females, which were categorized as nonalloparental, attacked the pups. The latency to approach pups (Fig. $1 B$ ) and time spent licking/grooming also did not differ significantly between the groups $(H=0.31, p>0.8$ for latency; $H=0.40, p>0.8$ for grooming). When only the animals that reached the criteria of being alloparental were compared, the latency to approach pups for CMV-OTR females $(140.2 \pm 65.2 \mathrm{~s})$ was not different from CMV-GFP $(62.5 \pm 39.3 \mathrm{~s})$ or sham $(169.4 \pm 51.7 \mathrm{~s})$ females $\left(F_{(2,7)}=1.27, p>0.3\right)$. There was also no difference in the amount of time that the alloparental CMV-OTR females spent licking pups compared with the alloparental CMV-GFP or sham females $\left(F_{(2,7)}=1.94, p>0.2\right)$ (Fig. $1 C)$. The total amount of time each group spent licking/grooming, hovering, and carrying the pups was also not different between the alloparental CMV-OTR (695.2 $\pm 77.1 \mathrm{~s})$, CMV-GFP $(387.5 \pm 132.7 \mathrm{~s})$, and sham $(503.8 \pm 82.8 \mathrm{~s})$ animals $\left(F_{(2,7)}=\right.$ $1.98, p>0.2)$.
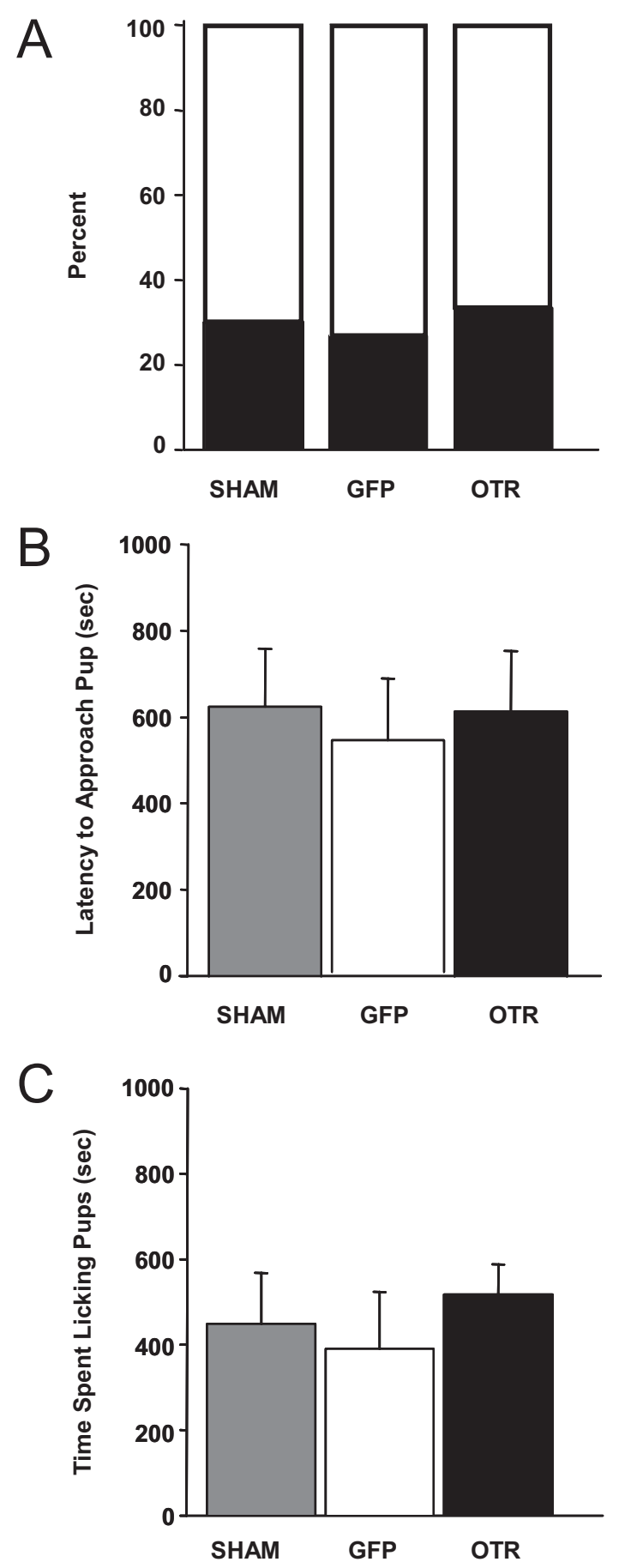

Figure 1. Alloparental behavior in sham, CMV-GFP, and CMV-OTR female prairie voles. $\boldsymbol{A}$, There was no effect of treatment on the proportion of females in each treatment group that displayed alloparental behavior. The dark bars represent the percentage of animals that were categorized as alloparental, while the light bars depict the number of females that attacked or ignored the pups. $\boldsymbol{B}$, The latency to approach pups was not different between groups. $\boldsymbol{C}$, There was no difference between groups in the amount of time the females spent licking pups, when only the females in each group that displayed alloparental behavior toward the pups were compared. Data are presented as mean \pm SEM.

\section{Mating behavior in prairie voles}

Mating behavior was not significantly affected by the females' previous surgical treatment. The latency to first intromission was not significantly different in males paired with CMV-OTR females compared with males mated to CMV-GFP or sham females $(H=5.043, p=0.08)$ (Fig. $2 A)$. Although the CMV-OTR group 
A

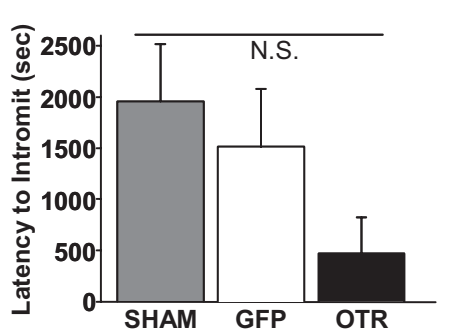

C

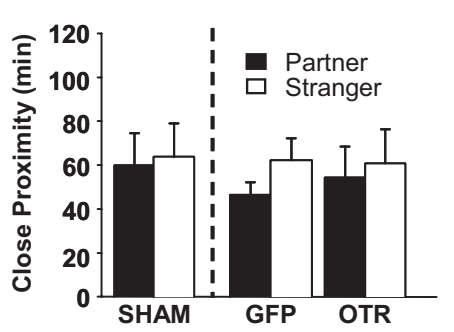

E

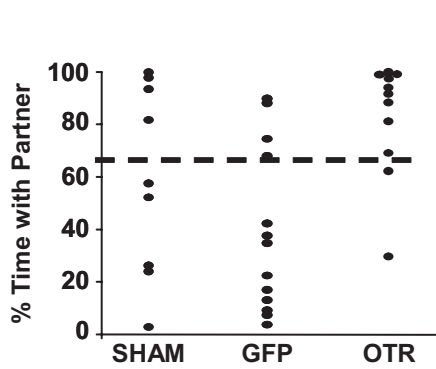

B
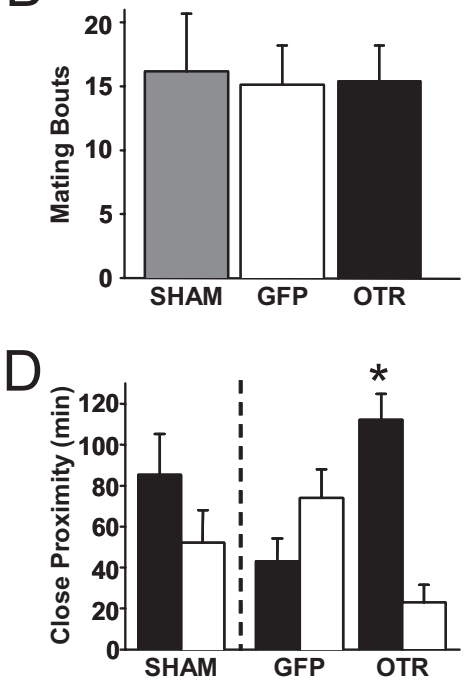

$\mathrm{F}$

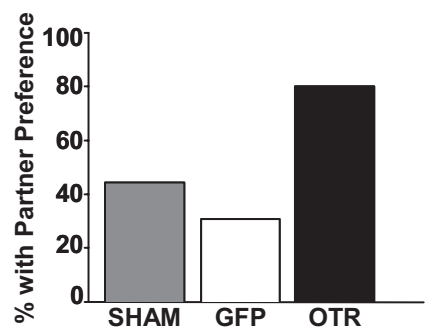

Figure 2. Mating and partner preference behavior in sham, CMV-GFP, and CMV-OTR female prairie voles. $\boldsymbol{A}, \boldsymbol{B}$, The latency to first intromission $(\boldsymbol{A})$ and the number of mating bouts $(\boldsymbol{B})$ were not significantly different between the groups. $\boldsymbol{C}$, After a $6 \mathrm{~h}$ cohabitation period, none of the groups displayed a significant preference for the partner over the stranger. $D$, After a cumulative $18 \mathrm{~h}$ cohabitation, CMV-OTR-injected females spent significantly more time with the partner than the stranger. The sham- and CMV-GFP-injected females did not spend significantly more time with either male at either time point. $\boldsymbol{E}$, Scatter plot illustrating the ratio of the time spent with partner/stranger for each individual in the groups. Females spending $>67 \%$ of their total social contact time with the partner (above the dashed line) are considered to have displayed a partner preference. $\boldsymbol{F}$, The overall percentage of animals in each group that displayed a partner preference. Data are presented as mean \pm SEM. ${ }^{*} p<0.001$. n.S., Not significant.

tended to mate sooner than the other groups, they did not mate more often. The number of mating bouts in the first hour did not differ in pairs containing CMV-OTR females from pairs containing CMV-GFP or sham females $\left(F_{(2,31)}=0.46, p>0.6\right)($ Fig. $2 B)$.

\section{Partner preference behavior in prairie voles}

After the $6 \mathrm{~h}$ cohabitation period, none of the groups displayed a significant partner preference (Fig. $2 C$ ). There was no main effect of treatment $\left(F_{(2,31)}=0.56, p>0.5\right)$ or time spent with the partner versus the stranger $\left(F_{(1,31)}=0.46, p>0.5\right)$. After an additional $12 \mathrm{~h}$ of cohabitation, there was no main effect of treatment $\left(F_{(2,29)}=0.78, p=0.5\right)$ or the amount of time spent with the partner versus stranger $\left(F_{(1,29)}=3.71, p=0.06\right)$. However, there was a significant interaction effect $\left(F_{(2,29)}=5.56, p=\right.$ 0.009). The post hoc test revealed that CMV-OTR females spent significantly more time in close proximity to the partner than to the stranger $(p<0.001)$ (Fig. $2 D)$. However, the CMV-GFP and sham females failed to show a partner preference after this period of time $(p>0.05)$ (Fig. $2 D$ ). In addition, $80 \%$ of CMV-OTRinjected voles reached the criteria of having a partner preference, i.e., spending twice as much time with the partner than the stranger, compared with only $31 \%$ of CMV-GFP-injected and $44 \%$ of sham animals (Fig. $2 E, F)$.
OTR and GFP expression in the NAcc of prairie voles

Autoradiography was done to determine placement of AAV injection and to verify that the CMV-OTR vector resulted in increased OTR binding compared with controls. As previously reported, there was significant individual variation in OTR binding in the NAcc of control CMV-GFP prairie voles (Fig. $3 A, B$ ). Distinct elevations in OTR binding were detected in the NAcc of CMV-OTR-injected prairie voles (Fig. 3C). In addition, GFP immunohistochemistry was performed on brain sections of CMV-GFP animals to determine the extent of expression in neurons of the NAcc. Clear labeling of cells with neuronal characteristics was detected, confirming that the CMV AAV vectors drove expression in neurons (Fig. 3E,F).

\section{Mating behavior in meadow voles}

No significant differences in mating behavior were observed between the treatment groups in meadow voles. The latency to first intromission was not different in males paired with CMV-OTR (1245.1 \pm 1465.9 s) females compared with males mated to control CMV-GFP (566.6 土 $989.8 \mathrm{~s}$ ) females $(t=128.0, p>0.2)$. The number of mating bouts in the first hour also did not differ in pairs containing CMV-OTR $(6.8 \pm 5.1)$ females from pairs containing CMV-GFP (9.5 \pm 4.4$)$ females $(t=1.42, p>0.1)$.

\section{Partner preference in meadow voles}

After a $24 \mathrm{~h}$ cohabitation period, none of the groups displayed a significant partner preference (Fig. 4A). There was no main effect of treatment $\left(F_{(1,20)}=0.19, p>0.6\right)$ or time spent with partner versus stranger $\left(F_{(1,20)}=0.09, p>0.7\right)$. After an additional $48 \mathrm{~h}$ of cohabitation, there was again no significant main effect of treatment $\left(F_{(1,19)}=0.65, p>0.4\right)$ or time spent with either female $\left(F_{(1,19)}=0.62, p>0.4\right)$ (Fig. $\left.4 B\right)$.

\section{OTR expression in the NAcc of meadow voles}

CMV-GFP-injected meadow voles had little or no OTR binding in the NAcc (Fig. 5A). In contrast, CMV-OTR-injected meadow voles had significant OTR binding in the NAcc, comparable with that of the prairie voles (Fig. $5 B$ ).

\section{Discussion}

Species differences in OTR density in the NAcc have been associated with species differences in mating strategy (social monogamy vs polygamy) and alloparental behavior, suggesting that variation in OTR receptor expression may underlie species differences in social organization and behavior (Insel et al., 1991; Young and Wang, 2004; Olazábal and Young, 2006b). Socially monogamous prairie voles have higher densities of OTR in the NAcc than nonmonogamous meadow and montane voles, and pharmacological blockade of those receptors prevents mating- 

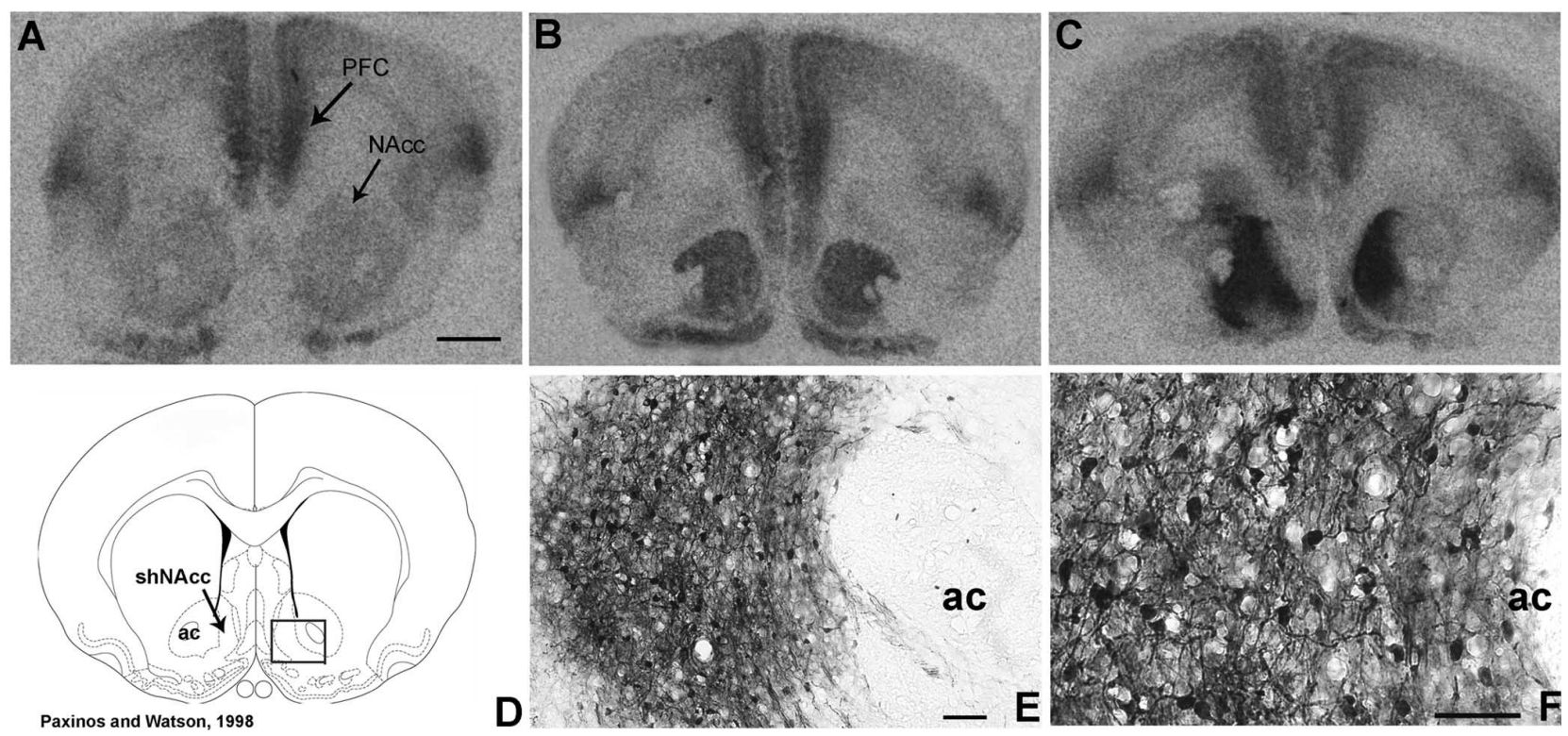

Figure 3. Analysis of OTR and GFP expression in CMV-OTR and CMV-GFP female prairie voles. OTR density was determined using receptor autoradiography. $A, B$, There was significant variation in the density of OTR binding in the NAcc of CMV-GFP females. This is in contrast to the prefrontal cortex (PFC), where there is little individual variation in OTR binding density. Scale bar, $1 \mathrm{~mm}$. $C$, CMV-OTR-injected females had elevated OTR binding in the NAcc relative to controls. $\boldsymbol{D}$, The dark square surrounding the NAcc depicts the position of the photomicrograph in $\boldsymbol{E}$. shNAcc, Shell of the NAcc; ac, anterior commissure. E, Photomicrograph (reprinted from Paxinos and Watson, 1998) taken using a 20 $\times$ objective of GFP-immunoreactivity in the shell of the NAcc of a CMV-GFP female. Immunoreactivity was distributed widely in soma as well as fiber processes. $\boldsymbol{F}$, Higher-magnification photomicrograph of the image in $\boldsymbol{E}$ illustrating the clear neuronal characteristics of the GFP-immunoreactive cells. Scale bars: $E, F, 50 \mu \mathrm{m}$.

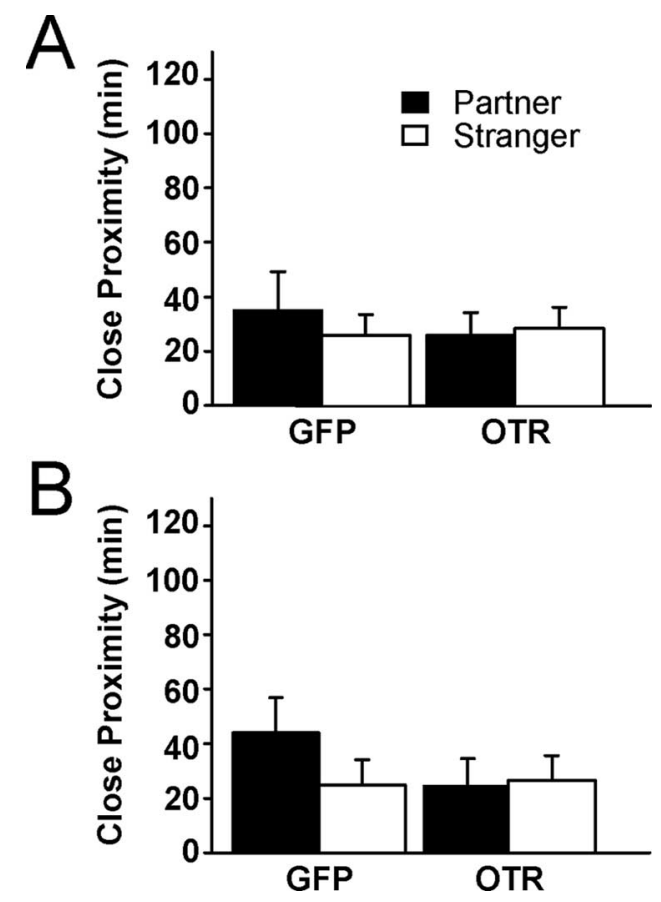

Figure 4. Partner preference behavior of female meadow voles after a $24 \mathrm{~h}$ cohabitation $(\boldsymbol{A})$ and after a cumulative $72 \mathrm{~h}$ cohabitation (B). CMV-OTR- and CMV-GFP-injected females did not show a partner preference. They spent equal amounts of time with the partner and the stranger at both time points. Data are presented as mean \pm SEM.

induced partner preference formation (Young et al., 2001; Olazábal and Young, 2006b). There is also significant individual variation in OTR density in the NAcc within prairie voles (Fig. $3 A, B$ ). OTR density in this region is positively correlated with individual variation in alloparental behavior of adult sexually naive female prairie voles (Young, 1999; Olazábal and Young, 2006b), and OTR antagonist administration into the NAcc eliminates this behavior (Olazábal and Young, 2006a). Therefore, in this study we sought to directly test the relationship between receptor density in the NAcc and affiliative behavior in voles, by using AAV gene transfer.

Our results show that, as predicted, female prairie voles with elevated levels of OTR in the NAcc display accelerated partner preference formation compared with females with lower OTR density (CMV-GFP or shams). Contrary to our prediction, there was no difference in alloparental behavior between groups, suggesting differential mechanisms by which accumbal OTR regulates partner preference formation and alloparental behavior. Our results support the hypothesis that individual differences in OTR expression contribute to intraspecies variation in some aspects of affiliative behavior. However, increasing OTR expression in the NAcc was not sufficient to induce partner preference formation in meadow voles, even after $72 \mathrm{~h}$ of cohabitation, suggesting that the species differences in accumbal OTR alone are not sufficient to explain the species differences in the ability to form partner preferences. It is important to note that there were no group differences in mating behavior in any of parameters examined. Therefore, the enhanced partner preference in the experimental prairie voles cannot be attributed to increased sexual activity during the initial cohabitation period.

Adult female prairie voles show remarkable individual variation in their display of alloparental care. Approximately $50 \%$ of sexually naive females will spontaneously retrieve, lick/groom, and hover over pups presented to them (Lonstein and De Vries, 1999; Bales and Carter, 2003; Olazábal and Young, 2005). There is also significant individual variation in OTR density in the NAcc among prairie voles (Young, 1999). Females with higher densities of OTR in the NAcc are more likely to display alloparental responsiveness than animals with lower OTR in this area. Thus it was surprising that elevating OTR density in the NAcc of prairie voles did not enhance alloparental behavior. The fact that these animals did show accelerated partner preference formation sug- 

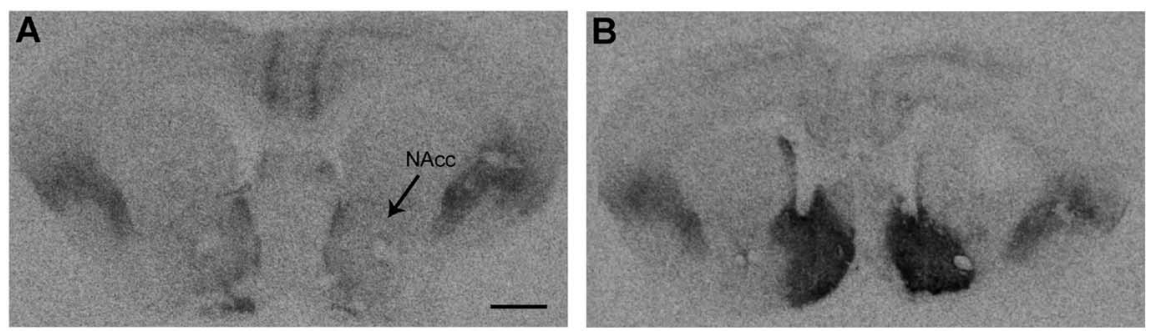

Figure 5. Receptor autoradiography illustrating OTR binding density in the NAcc of CMV-GFP $(\boldsymbol{A})$ and CMV-0TR $(\boldsymbol{B})$ meadow voles. Note that CMV-GFP female meadow voles had little or no OTR binding in the NAcc. However, OTR binding in the NAcc was dramatically elevated in CMV-OTR female meadow voles. Scale bar, $1 \mathrm{~mm}$.

gests that the OTR derived from the viral vector transgene was functionally coupled to signal transduction pathways in the NAcc.

We hypothesize that individual variation in OTR activation in the NAcc during development may play a more important role in producing intraspecies variation in alloparental behavior. The positive correlation in OTR density in the NAcc and alloparental behavior has been shown in juvenile prairie voles as well as adults (Olazábal and Young, 2006a,b). Alloparental behavior in prairie voles appears to be particularly sensitive to perturbations during development. For example, perinatal exposure to OT alters alloparental behavior in female prairie voles (Bales et al., 2007). Therefore, individuals with higher densities of OTR during development may experience increased OTR signaling in the NAcc, resulting in long-lasting neurochemical changes that increase the probability of displaying alloparental behavior as they become adults. If this hypothesis is correct, we would predict that increasing OTR expression in the NAcc neonatally would increase the frequency of alloparental behavior.

Another explanation for the failure of enhancing OTR expression in the NAcc to increase alloparental behavior is that variation in OTR expression in multiple brain regions may be necessary to produce the expected diversity in behavior. For example, OTR expression in the lateral septum is negatively correlated with alloparental behavior (Olazábal and Young, 2006a). Finally, it is also possible that variation in hormone exposure or social experience influences OTR density in the NAcc in addition to altering alloparental behavior. For example, the presence or absence of the father during development or perinatal manipulation of steroid hormones can influence the display of alloparental responsiveness in female prairie voles (Roberts et al., 1996, 1998; Lonstein and De Vries, 2000).

In male prairie voles, vasopressin plays a critical role in the display of paternal behavior as well as partner preference formation, paralleling the role of oxytocin in females (Winslow et al., 1993; Wang et al., 1994). Site-specific pharmacological studies demonstrate that $\mathrm{V} 1 \mathrm{aR}$ in the ventral pallidum, a major output of the NAcc, are critical for pair bond formation (Lim and Young, 2004). Increasing V1aR in the ventral pallidum using viral vector mediated gene transfer accelerates partner preference formation of male prairie voles (Pitkow et al., 2001), a finding that parallels the current study. Although overexpressing V1aR in the ventral pallidum of male meadow voles was not sufficient to induce paternal behavior, it did promote partner preference (Lim et al., 2004); in contrast, in the present study overexpression of OTR in the NAcc did not stimulate partner preference formation in female meadow voles.

There are several potential explanations for the failure of female meadow voles with elevated OTR in the NAcc to form partner preferences. First, species differences in OT release within the NAcc during mating may differ between female prairie voles and meadow voles. Although OTR localization differs between the species, both prairie voles and meadow voles have OTimmunoreactive fibers in the NAcc $(\mathrm{H}$. E. Ross and L. J. Young, unpublished data). In vivo microdialysis experiments have shown that mating stimulates OT release in the NAcc of female prairie voles, but parallel studies have not been performed in meadow voles (C. D. Cole and L. J. Young, unpublished data). It is possible that infusion of OT into CMV-OTRtreated animals would facilitate partner preference formation in meadow voles. However, it should be noted that in rats and sheep, vaginocervical stimulation increases central OT release (Kendrick et al., 1986; Sansone et al., 2002). Therefore it is likely that meadow voles are already experiencing a rise in accumbal OT with mating. Another explanation for the failure of NAcc OTR expression to stimulate partner preference formation in female meadow voles is that species differences in OTR expression in other brain regions are also necessary for pair bonding. For example, OTR density is also higher in the prefrontal cortex and lateral amygdala in prairie voles compared with nonmonogamous vole species (Insel et al., 1991; Young et al., 1996; Smeltzer et al., 2006). Therefore, elevating OTR expression in multiple sites may be necessary for stimulating mating-induced partner preferences in meadow voles. Finally, it is possible that multiple neurochemical differences between the species are responsible for species differences in behavior (e.g., dopamine, corticotropin-releasing factor) (Gingrich et al., 2000; Liu and Wang, 2003; Smeltzer et al., 2006; Lim et al., 2007).

There are several important caveats of our experimental approach that warrant discussion. First, the CMV-OTR likely increased OTR expression in all cell types in the injected area, including neuronal populations that normally do not respond to OT. However, it is possible that the transgenic OTR resulted in greater signaling in neurons that normally express endogenous OTR because of enhanced sensitization to OT released onto those neurons, or the presence of the appropriate downstream signaling molecules. Second, the area of transgene expression produced by viral vector infusion was not uniformly expressed over the entire rostrocaudal or mediolateral extent of the NAcc. In the CMV-OTR females, OTR expression was consistently elevated in the shell and adjacent core regions of the NAcc. However, it should be noted that shell of the NAcc has been most implicated in the regulation of partner preference formation and OTR density in this same region is more highly correlated with alloparental behavior than the core region.

This is the first study to demonstrate conclusively that variation in OTR expression in the brain can contribute to variation in social behavior. OT has been widely implicated in the regulation of several behaviors, including social information processing and memory, mate choice, maternal nurturing, and attachment (Dantzer et al., 1987; Kendrick, 2000; Ferguson et al., 2001; Kavaliers et al., 2003). There is now clear evidence that OT modulates human social cognition as well, including interpersonal trust, eye gaze, facial memory, and emotion perception (Kosfeld et al., 2005; Domes et al., 2007; Guastella et al., 2008; Savaskan et al., 2008). OT administration increases the retention of social cognition in a voice intonation task in autistic subjects (Hollander et al., 2007), and several genetic studies have reported modest associations between noncoding polymorphisms of the OTR gene 
and autism spectrum disorder (Wu et al., 2005; Jacob et al., 2007; Lerer et al., 2008; Yrigollen et al., 2008). There is limited information on the distribution of OTR, and nothing is known regarding individual variation in OTR density in the human brain. Our results suggest that variation in OTR density in specific brain regions may contribute to individual differences in social cognitive function in humans.

\section{References}

Bales KL, Carter CS (2003) Sex differences and developmental effects of oxytocin on aggression and social behavior in prairie voles (Microtus ochrogaster). Horm Behav 44:178-184.

Bales KL, van Westerhuyzen JA, Lewis-Reese AD, Grotte ND, Lanter JA, Carter CS (2007) Oxytocin has dose-dependent developmental effects on pair-bonding and alloparental care in female prairie voles. Horm Behav 52:274-279.

Curtis JT, Wang Z (2005a) Ventral tegmental area involvement in pair bonding in male prairie voles. Physiol Behav 86:338 -346.

Curtis JT, Wang Z (2005b) Glucocorticoid receptor involvement in pair bonding in female prairie voles: the effects of acute blockade and interactions with central dopamine reward systems. Neuroscience 134:369-376.

Dantzer R, Bluthe RM, Koob GF, Le Moal M (1987) Modulation of social memory in male rats by neurohypophyseal peptides. Psychopharmacology 91:363-368.

Domes G, Heinrichs M, Michel A, Berger C, Herpertz SC (2007) Oxytocin improves "mind-reading" in humans. Biol Psychiatry 61:731-733.

Ferguson JN, Aldag JM, Insel TR, Young LJ (2001) Oxytocin in the medial amygdala is essential for social recognition in the mouse. J Neurosci 21:8278-8285.

Gingrich B, Liu Y, Cascio C, Wang Z, Insel TR (2000) Dopamine D2 receptors in the nucleus accumbens are important for social attachment in female prairie voles (Microtus ochrogaster). Behav Neurosci 114:173-183.

Gruderadams S, Getz LL (1985) Comparison of the mating system and paternal behavior in Microtus ochrogaster and Microtus pennsylvanicus. J Mammal 66:165-167.

Guastella AJ, Mitchell PB, Dadds MR (2008) Oxytocin increases gaze to the eye region of human faces. Biol Psychiatry 63:3-5.

Hollander E, Bartz J, Chaplin W, Phillips A, Sumner J, Soorya L, Anagnostou E, Wasserman S (2007) Oxytocin increases retention of social cognition in autism. Biol Psychiatry 61:498-503.

Insel TR, Shapiro LE (1992) Oxytocin receptor distribution reflects social organization in monogamous and polygamous voles. Proc Natl Acad Sci U S A 89:5981-5985.

Insel TR, Gelhard R, Shapiro LE (1991) The comparative distribution of forebrain receptors for neurohypophyseal peptides in monogamous and polygamous mice. Neuroscience 43:623-630.

Jacob S, Brune CW, Carter CS, Leventhal BL, Lord C, Cook EH Jr (2007) Association of the oxytocin receptor gene (OXTR) in Caucasian children and adolescents with autism. Neurosci Lett 417:6-9.

Kavaliers M, Colwell DD, Choleris E, Agmo A, Muglia LJ, Ogawa S, Pfaff DW (2003) Impaired discrimination of and aversion to parasitized male odors by female oxytocin knockout mice. Genes Brain Behav 2:220-230.

Kendrick KM (2000) Oxytocin, motherhood and bonding. Exp Physiol 85 [Suppl 1]:111S-124S.

Kendrick KM, Keverne EB, Baldwin BA, Sharman DF (1986) Cerebrospinal fluid levels of acetylcholinesterase, monoamines and oxytocin during labour, parturition, vaginocervical stimulation, lamb separation and suckling in sheep. Neuroendocrinology 44:149-156.

Kosfeld M, Heinrichs M, Zak PJ, Fischbacher U, Fehr E (2005) Oxytocin increases trust in humans. Nature 435:673-676.

Lerer E, Levi S, Salomon S, Darvasi A, Yirmiya N, Ebstein RP (2008) Association between the oxytocin receptor (OXTR) gene and autism: relationship to Vineland Adaptive Behavior Scales and cognition. Mol Psychiatry 13:980-988.

Lim MM, Young LJ (2004) Vasopressin-dependent neural circuits underlying pair bond formation in the monogamous prairie vole. Neuroscience 125:35-45.

Lim MM, Wang Z, Olazábal DE, Ren X, Terwilliger EF, Young LJ (2004) Enhanced partner preference in a promiscuous species by manipulating the expression of a single gene. Nature 429:754-757.
Lim MM, Liu Y, Ryabinin AE, Bai Y, Wang Z, Young LJ (2007) CRF receptors in the nucleus accumbens modulate partner preference in prairie voles. Horm Behav 51:508-515.

Liu Y, Wang ZX (2003) Nucleus accumbens oxytocin and dopamine interact to regulate pair bond formation in female prairie voles. Neuroscience 121:537-544.

Lonstein JS, De Vries GJ (1999) Sex differences in the parental behaviour of adult virgin prairie voles: independence from gonadal hormones and vasopressin. J Neuroendocrinol 11:441-449.

Lonstein JS, De Vries GJ (2000) Influence of gonadal hormones on the development of parental behavior in adult virgin prairie voles (Microtus ochrogaster). Behav Brain Res 114:79-87.

Olazábal DE, Young LJ (2005) Variability in "spontaneous" maternal behavior is associated with anxiety-like behavior and affiliation in naive juvenile and adult female prairie voles (Microtus ochrogaster). Dev Psychobiol 47:166-178.

Olazábal DE, Young LJ (2006a) Species and individual differences in juvenile female alloparental care are associated with oxytocin receptor density in the striatum and the lateral septum. Horm Behav 49:681-687.

Olazábal DE, Young LJ (2006b) Oxytocin receptors in the nucleus accumbens facilitate "spontaneous" maternal behavior in adult female prairie voles. Neuroscience 141:559-568.

Paxinos G, Watson C (1998) The rat brain in stereotaxic coordinates, Ed 4. San Diego: Academic.

Pitkow LJ, Sharer CA, Ren X, Insel TR, Terwilliger EF, Young LJ (2001) Facilitation of affiliation and pair-bond formation by vasopressin receptor gene transfer into the ventral forebrain of a monogamous vole. J Neurosci 21:7392-7396.

Roberts RL, Zullo A, Gustafson EA, Carter CS (1996) Perinatal steroid treatments alter alloparental and affiliative behavior in prairie voles. Horm Behav 30:576-582.

Roberts RL, Williams JR, Wang AK, Carter CS (1998) Cooperative breeding and monogamy in prairie voles: influence of the sire and geographical variation. Anim Behav 55:1131-1140.

Sansone GR, Gerdes CA, Steinman JL, Winslow JT, Ottenweller JE, Komisaruk BR, Insel TR (2002) Vaginocervical stimulation releases oxytocin within the spinal cord in rats. Neuroendocrinology 75:306-315.

Savaskan E, Ehrhardt R, Schulz A, Walter M, Schächinger H (2008) Postlearning intranasal oxytocin modulates human memory for facial identity. Psychoneuroendocrinology 33:368-374.

Smeltzer MD, Curtis JT, Aragona BJ, Wang Z (2006) Dopamine, oxytocin, and vasopressin receptor binding in the medial prefrontal cortex of monogamous and promiscuous voles. Neurosci Lett 394:146-151.

Wang Z, Young LJ (1997) Ontogeny of oxytocin and vasopressin receptor binding in the lateral septum in prairie and montane voles. Brain Res Dev Brain Res 104:191-195.

Wang Z, Ferris CF, De Vries GJ (1994) Role of septal vasopressin innervation in paternal behavior in prairie voles (Microtus ochrogaster). Proc Natl Acad Sci U S A 91:400-404.

Williams JR, Catania KC, Carter CS (1992) Development of partner preferences in female prairie voles (Microtus ochrogaster): the role of social and sexual experience. Horm Behav 26:339-349.

Winslow JT, Hastings N, Carter CS, Harbaugh CR, Insel TR (1993) A role for central vasopressin in pair bonding in monogamous prairie voles. Nature 365:545-548.

Wu S, Jia M, Ruan Y, Liu J, Guo Y, Shuang M, Gong X, Zhang Y, Yang X, Zhang D (2005) Positive association of the oxytocin receptor gene (OXTR) with autism in the Chinese Han population. Biol Psychiatry 58:74-77.

Young LJ (1999) Frank A. Beach Award. Oxytocin and vasopressin receptors and species-typical social behaviors. Horm Behav 36:212-221.

Young LJ, Wang Z (2004) The neurobiology of pair bonding. Nat Neurosci 7:1048-1054.

Young LJ, Huot B, Nilsen R, Wang Z, Insel TR (1996) Species differences in central oxytocin receptor gene expression: comparative analysis of promoter sequences. J Neuroendocrinol 8:777-783.

Young LJ, Lim MM, Gingrich B, Insel TR (2001) Cellular mechanisms of social attachment. Horm Behav 40:133-138.

Yrigollen CM, Han SS, Kochetkova A, Babitz T, Chang JT, Volkmar FR, Leckman JF, Grigorenko EL (2008) Genes controlling affiliative behavior as candidate genes for autism. Biol Psychiatry 63:911-916. 